\title{
Central obesity associates with renal hyperfiltration in the non-diabetic general population: a cross-sectional study
}

\author{
Vidar Tor Nyborg Stefansson ${ }^{1 *}$, Jørgen Schei ${ }^{1}$, Trond Geir Jenssen ${ }^{1,3}$, Toralf Melsom ${ }^{1,2}$ and Bjørn Odvar Eriksen ${ }^{1,2}$
}

\begin{abstract}
Background: Obesity is a risk factor for end-stage renal disease. Renal hyperfiltration, defined as an abnormally high glomerular filtration rate (GFR), is a link in the causal chain between diabetes and chronic kidney disease. Whether obesity is associated with hyperfiltration in the non-diabetic general population, remains unresolved due to a lack of consensus regarding the definition of hyperfiltration and the limited precision of high-range GFR estimations with creatinine and/or cystatin C.

Methods: 1555 middle-aged participants without diabetes, renal or cardiovascular disease were enrolled from the general population in the Renal lohexol Clearance Survey from the 6th Tromsø Study (RENIS-T6) between 2007 and 2009. Obesity was assessed using the body mass index (BMI), waist circumference (WC) and the waist-hip ratio (WHR). GFR was measured by iohexol clearance. Dichotomous variables for hyperfiltration were based on two alternative definitions using unadjusted GFR ( $\mathrm{mL} / \mathrm{min}$ ) above the 90th percentile. The 90th percentile was age-, sex- and heightspecific in one definition and age-, sex-, height- and weight-specific in the other.
\end{abstract}

Results: In multivariable adjusted logistic regression models, only WHR was consistently associated with hyperfiltration based on both definitions. For the definition based on the age-, sex-, height- and weight-specific 90th percentile, the association with the WHR (odds ratios (95\% confidence intervals)) for hyperfiltration was 1.48 (1.08-2.02) per 0.10 WHR increase.

Conclusions: Central obesity is associated with hyperfiltration in the general population. The WHR may serve as a better indicator of the renal effects of obesity than BMI or WC.

Keywords: Body mass index, Chronic kidney disease, Glomerular filtration rate, Glomerular hyperfiltration, Waist circumference, Waist-hip ratio

\section{Background}

The prevalence of obesity, defined as a body mass index $(\mathrm{BMI}) \geq 30 \mathrm{~kg} / \mathrm{m}^{2}$, has increased rapidly in high-income nations over the last few decades and is steadily growing in many lower-income countries as well [1]. Obesity is a well-known risk factor for cardiovascular disease, hypertension and diabetes $[2,3]$. These diseases are, in turn, well-established risk factors for chronic kidney disease (CKD) and end-stage renal disease (ESRD) [4-7]. However, there is also evidence of a direct causal connection

\footnotetext{
* Correspondence: vidar.stefansson@uit.no

${ }^{1}$ Metabolic and Renal Research Group, Faculty of Health Sciences, UiT The

Arctic University of Norway, Tromsø, Norway

Full list of author information is available at the end of the article
}

between obesity and ESRD, independent of hypertension and diabetes $[8,9]$.

Renal hyperfiltration (RHF), or an abnormally high glomerular filtration rate (GFR), has been postulated to represent an early stage in the development of CKD [10], most clearly observed in diabetic nephropathy [11]. RHF is also associated with several established CKD risk factors, including hypertension $[12,13]$ and smoking $[14,15]$. A large longitudinal study by Park et al. of 43,503 Korean health screening participants found that a RHF definition based on eGFR was associated with all-cause mortality, even when adjusted for age, sex, muscle mass, diabetes and hypertension [16]. Although several studies have been 
conducted on the relationship between obesity and RHF [17-25], it remains unclear whether these two conditions are also associated in the general nondiabetic population. The most important reason has been that there is currently no consensus on the definition of the term "hyperfiltration". Most investigators who defined RHF in their studies used a single GFR cutoff point and adjusted their definition for no other variable than body surface area (BSA) [26]. Although there is no generally accepted way of defining RHF, it has been suggested that the definition should use age and sex-specific cut-offs and also some measure of correction for body size $[26,27]$.

Another methodological problem has been that previous epidemiological studies used GFR estimates based on creatinine and cystatin C, rather than GFR measurements [21-25]. Estimated GFR is inaccurate for highrange GFR [28-30] and can be confounded by associations with non-GFR-related factors [31, 32]. Studies on obesity and RHF using measured GFR (mGFR) have been limited by small sample sizes [17-19] and the lack of adjustment for confounding variables [20].

In the Renal Iohexol Clearance Survey in Tromsø 6 (RENIS-T6), we measured GFR with iohexol clearance in 1627 middle-aged subjects from the general population. The aim of the present study was to examine the relationship between obesity and two alternative definitions of RHF.

\section{Methods}

\section{Subjects}

RENIS-T6 was conducted from 2007 to 2009 as a substudy of the sixth Tromsø Study (Tromsø 6). The RENIST6 cohort consisted of a representative sample of 1627 persons from the general population of Troms $\varnothing$ who were between 50 to 62 years of age and without self-reported diabetes mellitus, cardiovascular or kidney disease (Fig. 1); the cohort has previously been described in detail [28].

Subjects were excluded from the present study if they had previously undiagnosed diabetes mellitus (hemoglobin A1c $\geq 6.5 \%$ and/or fasting plasma glucose $\geq 7.0 \mathrm{mmol} / \mathrm{L}$ ) or if they lacked waist or hip circumference measurements.

Smoking status was ascertained as part of a detailed questionnaire in the Tromsø 6 study. Previous smokers were grouped with non-smokers for the purposes of this study. Medication use was ascertained separately in the RENIS-T6 study. Antihypertensive medication use was categorized into six categories: beta-blockers, calcium channel blockers, diuretics, angiotensin converting enzyme-inhibitors, angiotensin-II receptor blockers, and other antihypertensive medications.

\section{lohexol-clearance measurements}

Examination of the subjects started between 08:00 and 10:00 AM. All subjects had fasted and abstained from smoking since midnight, and they were instructed not to use non-steroid anti-inflammatory drugs or eat large

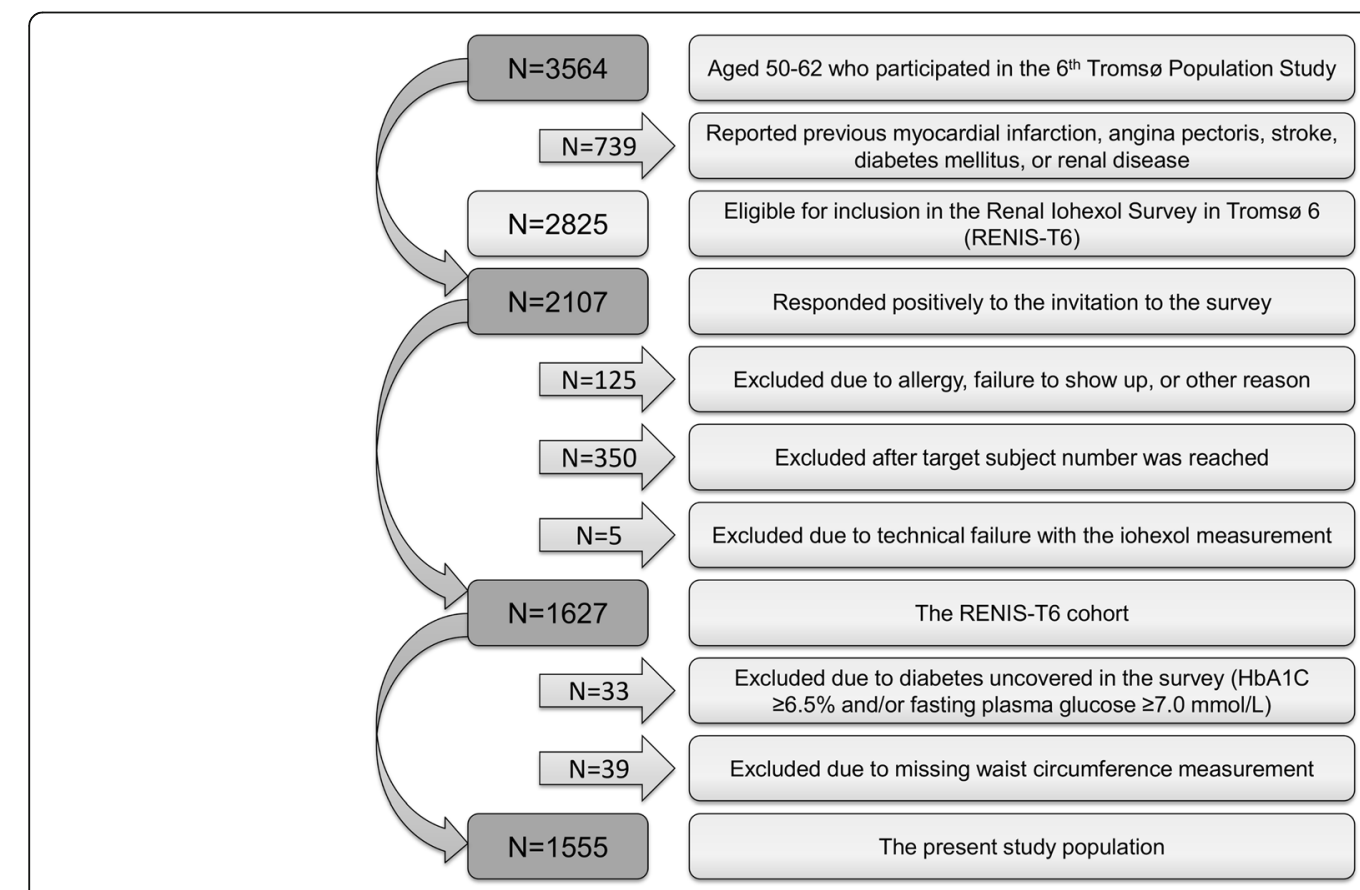

Fig. 1 Inclusion of subjects in the RENIS-T6 cohort and the present study population 
quantities of meat during the preceding $48 \mathrm{~h}$. Subjects were instructed to drink two to three glasses of water before arrival. A Teflon catheter was placed in an antecubital vein and was flushed with $30 \mathrm{~mL}$ of isotonic saline. Five milliliters of iohexol (Omnipaque, $300 \mathrm{mg} / \mathrm{mL}$; Amersham Health) was injected, and the syringe was weighed before and after injection. GFR was measured as the single-sample plasma clearance of iohexol, a method that has been validated against gold standard methods [33], and analyzed using high-precision liquid chromatography as described by Nilsson-Ehle [34]. The analytical variation coefficient for the study period was $3.0 \%$. Jacobsson's method was used to calculate the GFR [35]. Further procedural details have been described previously [28].

\section{Laboratory measurements}

Glucose, low-density and high-density lipoprotein cholesterol, and triglycerides were measured on a Modular P800 (Roche Diagnostics, Basel, Switzerland). The insulin concentration was measured with an enzyme-linked immunosorbent assay kit (DRG Instruments, Marburg, Germany), with intra- and interassay coefficients of variation of $4.7 \%$ and $6.3 \%$, respectively. Insulin resistance was expressed by the homeostasis model assessment (HOMA-IR), calculated by multiplying fasting glucose $(\mathrm{mmol} / \mathrm{L})$ by fasting insulin (mU/L) and dividing the result by 22.5 [36].

\section{Blood pressure measurement}

Office blood pressure (BP) was measured at the study site using an automated device (model UA799; A\&D, Tokyo, Japan) after 2 min of rest. Daytime ambulatory BP was measured using weighted daytime (10:0022:00) averages of BP measured at 20-min intervals. Further details of the BP measurements have been described previously [37].

\section{Body measurements}

Waist and hip circumferences, along with height, were measured as part of the main Troms $\varnothing 6$ study at a median (interquartile range) of 5.2 (3.0-6.2) months before the RENIS-T6 investigations. Body weight was measured in the RENIS-T6 study to the nearest $0.1 \mathrm{~kg}$ on a SECA digital scale (SECA, Hamburg, Germany). The same weight scale was used for all subjects and was calibrated just before the study began. Height was measured to the nearest centimeter with a wall-mounted measuring tape.
BMI was defined as height in meters divided by weight in kilograms squared. Waist and hip circumferences were measured horizontally over the umbilicus after exhalation and at the greatest protrusion of the buttocks, respectively. The WHR was calculated as the waist circumference divided by the hip circumference.

Subjects were classified into overweight and obesity categories based on cut-off values used by the World Health Organization and the International Diabetes Federation for European populations. BMI classes of 18.5-24.9, 25.0-29.9 and $\geq 30.0$ define normal weight, overweight and obesity, respectively. WC categories of $>94 \mathrm{~cm}$ for men and $>80 \mathrm{~cm}$ for women represent "increased risk of metabolic complications", while a WC of $>102 \mathrm{~cm}$ for men or $>88 \mathrm{~cm}$ for women, or a WHR of $\geq 0.90$ for men or $\geq 0.85$ for women represents "substantially increased risk" [38].

There were only four subjects with BMI $<18.5$, these were grouped with the normal BMI (18.5-24.9) group for the purposes of this study. Fifty-seven subjects had BMI between 35.0 and 39.9 , and 5 subjects had $\mathrm{BMI} \geq 40.0$, these were included in the $\mathrm{BMI} \geq 30.0$ group.

\section{Definitions of hyperfiltration}

The dichotomous variables for hyperfiltration were defined as unadjusted (absolute) GFR ( $\mathrm{mL} / \mathrm{min}$ ) above the 90th percentile. We used two alternative definitions where the 90th percentile was either age-/sex- and height-specific $\left(\mathrm{RHF}_{\text {Height }}\right)$ or age-/sex-/height and weight-specific $\left(\mathrm{RHF}_{\text {Weight/height }}\right)$ (Table 1$)$.

In both cases, the respective 90th percentiles were calculated from multiple linear regression models, with the natural logarithm $(\mathrm{ln})$ of unadjusted GFR $(\mathrm{mL} / \mathrm{min})$ as the dependent variable. For $\mathrm{RHF}_{\text {Height, }}$ sex, $\ln ($ age $)$ and $\ln$ (height) were used as independent variables, and for $\mathrm{RHF}_{\text {Weight/height }} \ln$ (body weight) was added (Additional file 1: Table S1). A subject was defined as having $\mathrm{RHF}_{\text {Height }}$ or $\mathrm{RHF}_{\text {Weight/height }}$ if her regression residual was greater than the 90th percentile in the distribution of residuals in the regression analyses for the respective RHF definition (Table 1). This implies that the GFR cutoff for RHF for each individual depended on sex, age and height $\left(\mathrm{RHF}_{\text {Height }}\right)$ or sex, age, height and body weight $\left(\mathrm{RHF}_{\mathrm{Weight} / \mathrm{height}}\right)$. As an illustration, the GFR cutoff points for RHF in a male and female study participant with average measurements of age, height and weight are shown in Additional file 1: Table S2.

Table 1 Alternative definitions of renal hyperfiltration based on different adjustment variables in multiple linear regression

\begin{tabular}{llll}
\hline RHF definition & Dependent variable & Independent variables & Definition of dichotomous RHF variable \\
\hline RHF Height $_{\text {H }}$ & Logarithm of absolute GFR (in $\mathrm{mL} / \mathrm{min}$ ) & Sex and logarithms of height and age & Residual $>90$ th percentile \\
RHF Weight/height & Logarithm of absolute GFR (in $\mathrm{mL} / \mathrm{min}$ ) & Sex and logarithms of weight, height and age & Residual $>90$ th percentile \\
\hline
\end{tabular}

In both definitions, renal hyperfiltration was defined as residual > 90th percentile in multiple linear regression analysis with the independent variables listed above

RHF Renal hyperfiltration, GFR Glomerular filtration rate 


\section{Statistical analysis}

The characteristics of the study population were tabulated as the mean (standard deviation) or median (interquartile range) for variables with skewed distributions. Pearson's $X^{2}$ test, Welch's $t$-test and the Mann-Whitney
$U$ test were used to calculate p-values for differences between the WHR groups, classified by the World Health Organization cut-off for WHR.

Separate multiple logistic regression analyses were performed with each of the two alternative RHF variables

Table 2 Characteristics of the study population classified by World Health Organization waist-hip ratio cut-off point

\begin{tabular}{|c|c|c|c|c|c|}
\hline \multirow[b]{2}{*}{ Subjects } & \multicolumn{2}{|c|}{ Normal waist-hip ratio ${ }^{a}$} & \multicolumn{2}{|c|}{ Increased waist-hip ratio ${ }^{b}$} & \multirow[t]{2}{*}{$P$-value } \\
\hline & 432 & $27.8 \%$ & 1123 & $72.2 \%$ & \\
\hline Male gender & 142 & $32.9 \%$ & 618 & $55.0 \%$ & $<0.001$ \\
\hline Age & 58.1 & $54.1-61.2$ & 58.8 & $55.0-61.6$ & 0.01 \\
\hline Waist-hip-ratio & 0.824 & 0.046 & 0.941 & 0.055 & \\
\hline Waist circumference (cm) & 83.5 & 7.6 & 99.3 & 9.7 & $<0.001$ \\
\hline Body Mass Index $\left(\mathrm{kg} / \mathrm{m}^{2}\right)$ & 24.6 & 3.0 & 28.3 & 3.8 & $<0.001$ \\
\hline Height (cm) & 168.9 & 8.5 & 171.3 & 8.8 & $<0.001$ \\
\hline Weight (kg) & 70.2 & 10.8 & 83.1 & 13.8 & $<0.001$ \\
\hline Daily smokers & 89 & $20.6 \%$ & 222 & $19.8 \%$ & 0.71 \\
\hline Daytime ambulatory systolic BP (mmHg) & 126.1 & 12.6 & 131.5 & 13.0 & $<0.001$ \\
\hline Daytime ambulatory diastolic BP (mmHg) & 79.9 & 8.6 & 82.9 & 8.6 & $<0.001$ \\
\hline Nighttime ambulatory systolic BP (mmHg) & 108.5 & 12.2 & 111.9 & 12.2 & $<0.001$ \\
\hline Nighttime ambulatory diastolic BP (mmHg) & 64.9 & 8.6 & 67.0 & 8.4 & $<0.001$ \\
\hline Office systolic BP (mmHg) & 123.3 & 17.1 & 131.8 & 17.1 & $<0.001$ \\
\hline Office diastolic BP (mmHg) & 79.9 & 10.0 & 84.7 & 9.3 & $<0.001$ \\
\hline Hypertension ${ }^{c}$ & 95 & $22.0 \%$ & 437 & $38.9 \%$ & $<0.001$ \\
\hline ACE-inhibitor use & 6 & $1.3 \%$ & 22 & $2.0 \%$ & 0.45 \\
\hline Angiotensin II-receptor blocker use & 13 & $3.0 \%$ & 116 & $10.3 \%$ & $<0.001$ \\
\hline Calcium-channel blocker use & 7 & $1.6 \%$ & 71 & $6.3 \%$ & $<0.001$ \\
\hline Beta-blocker use & 7 & $1.6 \%$ & 60 & $5.3 \%$ & 0.001 \\
\hline Diuretica use & 17 & $3.9 \%$ & 119 & $10.6 \%$ & $<0.001$ \\
\hline Other anti-hypertensive medicine use & 0 & - & 1 & $<0.1 \%$ & 0.54 \\
\hline Fasting glucose (mmol/L) & 5.13 & 0.44 & 5.39 & 0.48 & $<0.001$ \\
\hline Fasting insulin (m/U/L) & 6.50 & $4.37-8.69$ & 9.47 & $6.90-13.65$ & $<0.001$ \\
\hline HOMA-IR & 1.47 & $0.98-2.01$ & 2.30 & $1.60-3.37$ & $<0.001$ \\
\hline $\mathrm{HbA1c}(\%)$ & 5.46 & 0.30 & 5.57 & 0.34 & $<0.001$ \\
\hline Cholesterol (mmol/L) & 5.53 & 0.89 & 5.67 & 0.96 & 0.008 \\
\hline LDL cholesterol (mmol/L) & 3.45 & 0.83 & 3.73 & 0.86 & $<0.001$ \\
\hline HDL cholesterol (mmol/L) & 1.75 & 0.44 & 1.45 & 0.39 & $<0.001$ \\
\hline Triglycerides (mmol/L) & 0.8 & $0.6-1.1$ & 1.1 & $0.8-1.6$ & $<0.001$ \\
\hline Cholesterol-lowering drug use & 21 & $4.9 \%$ & 79 & $7.0 \%$ & 0.12 \\
\hline Absolute GFR (ml/min) & 93.8 & 16.0 & 104.0 & 20.4 & $<0.001$ \\
\hline GFR $\left(\mathrm{ml} / \mathrm{min} / 1.73 \mathrm{~m}^{2}\right)$ & 90.1 & 13.0 & 92.0 & 14.8 & 0.02 \\
\hline RHFHeight & 19 & $4.4 \%$ & 137 & $12.2 \%$ & $<0.001$ \\
\hline RHFWeight/height & 30 & $6.9 \%$ & 123 & $11.0 \%$ & 0.02 \\
\hline
\end{tabular}

Data represented as number of subjects (percentage), median (interquartile range) or mean (standard deviation)

$B P$ Blood pressure, $A C E$ Angiotensin converting enzyme, HOMA-IR Homeostatic model assessment of insulin resistance, $L D L$ Low density lipoprotein, HDL High density lipoprotein, $\mathrm{HbA1c}$ Hemoglobin A1c, GFR Glomerular filtration rate

${ }^{\mathrm{a}}$ Female $<0.85$, male $<0.90$

${ }^{b}$ Female $\geq 0.85$, male $\geq 0.90$

'Office systolic BP $\geq 140 \mathrm{mmHg}$, office diastolic BP $\geq 90 \mathrm{mmHg}$ and/or use of antihypertensive medication 
(Table 1) as the dependent dichotomous variable and categorical or continuous indices of obesity as the independent variable. Adjustments were made for age, sex, number of cigarettes smoked daily, ambulatory daytime systolic and diastolic BP and their interaction, and individual categories of antihypertensive medication (Model 1). Mathisen et al. found a statistically significant interaction between these BP variables and GFR in the same study population as the present study [37], which is why this interaction model was included. Model 2 included Model 1 and a dichotomous variable for a metabolically unhealthy lipid profile, defined as high-density lipoprotein cholesterol levels $<1.03 \mathrm{mmol} / \mathrm{L}$ in men or $<1.29 \mathrm{mmol} / \mathrm{L}$ in women, elevated triglyceride levels of $\geq 1.7 \mathrm{mmol} / \mathrm{L}$, and/or use of lipid-lowering medication. The variables in Model 2 constitute two of the five established criteria used to define metabolic syndrome [39]. Model 3 included Model 1, fasting plasma glucose and insulin levels, and HOMA-IR. Model 4 included all models. Additionally, linear regression analyses using absolute and BSA-adjusted GFR as dependent variables and the same independent variables as above were performed.

Fractional polynomial regression analyses [40] were performed to see whether any obesity variables had nonlinear relationships with either RHF variable or with mGFR as a continuous variable, adjusting for the same variables as in Model 4.

Statistical significance was set at $p<0.05$. Statistical analysis was performed using STATA MP 14.0 software (www.stata.com).

\section{Results}

\section{Study population}

Thirty-three of the 1627 study subjects in the RENIS-T6 cohort were excluded due to undiagnosed diabetes mellitus. Another 39 subjects were excluded because of missing WC measurements, leaving 1555 subjects eligible for the current study (Fig. 1).

The analysis of the study population showed several statistically significant associations between study variables and WHR categories (Table 2). A substantially higher percentage of males than females were obese according to the cut-off values. Subjects with a high WHR were, on average, older, had a higher absolute and BSAadjusted GFR, higher BP, worse lipid and glucose profiles, and were more likely to use lipid- or BP-reducing drugs. There was a clear relationship between a greater WHR and higher GFR (Fig. 2). The vast majority of the population was overweight or obese (Fig. 3).

\section{Hyperfiltration and obesity}

The RHF definitions (Table 1) resulted in overlap, with 115 hyperfiltrating subjects having RHF by both

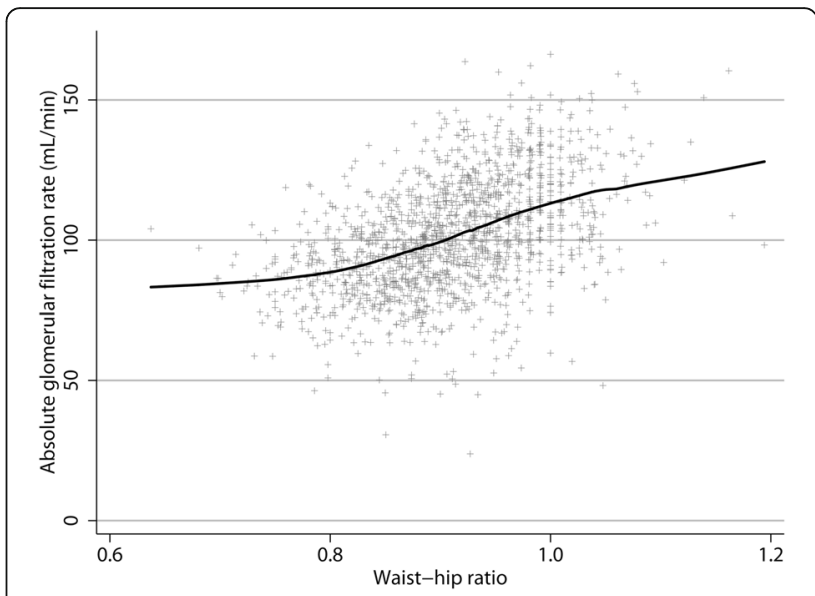

Fig. 2 Scatterplot with locally weighted scatterplot smoothing (LOWESS) showing the relationship between the waist-hip ratio and glomerular filtration rate

definitions. Forty-one subjects had only $\mathrm{RHF}_{\mathrm{Height}}$, while 38 had only $\mathrm{RHF}_{\text {Weight/height }}$.

In the logistic regression analyses, there was a statistically significant association between $\mathrm{RHF}_{\text {Height }}$ and all obesity variables, categorical and continuous, except for the intermediate WC category, even in the fully adjusted Model 4 (Table 3). This relationship remained significant when body weight was added to the regression analyses as an independent variable (Additional file 1: Table S3).

With $\mathrm{RHF}_{\mathrm{Weight} / \mathrm{height}}$, these relationships changed. Only the WHR as a continuous variable was consistently associated with $\mathrm{RHF}_{\mathrm{Weight} / \text { height }}$ across all the models $(p<0.05)$. In Model 1, the odds ratio (confidence interval) for $\mathrm{RHF}_{\text {Weight/height }}$ was 1.66 (1.24-2.21) for each 0.10 increase in the WHR. The association was attenuated, but remained significant, when metabolic risk factors were added as independent variables in Models 2, 3 and 4 (Table 3).

Linear regression analyses with absolute and BSAadjusted GFR as dependent variables and the same independent variables as above showed significant positive relationships between body size variables and absolute GFR, but no statistically significant relationship with BSA-adjusted GFR (Additional file 1: Table S4).

Interaction analyses were performed on the obesity variables and sex as well as the obesity variables and the dichotomous variable for an unhealthy lipid profile (defined in Model 2); but no statistically significant interactions were found. No statistically significant non-linear relationship was found between any obesity variables and the RHF variables or mGFR when analyzed in fractional polynomial regression models.

\section{Discussion}

In this study of non-diabetic, middle-aged subjects from the general population, higher WHR, but not BMI or 


\begin{tabular}{|c|c|c|c|}
\hline Categories & Body mass index (BMI) & Waist circumference (WC) & Waist-hip ratio (WHR) \\
\hline \multirow{2}{*}{ Normal } & \multirow{2}{*}{$18.5-24.9 \mathrm{~kg} / \mathrm{m}^{2}$} & $\delta^{\lambda} \leq 94 \mathrm{~cm}$ & $\delta<0.90$ \\
\hline & & 오 $\leq 80 \mathrm{~cm}$ & $q<0.85$ \\
\hline \multirow{2}{*}{ Overweight } & \multirow{2}{*}{$25.0-29.9 \mathrm{~kg} / \mathrm{m}^{2}$} & ठิ $95-102 \mathrm{~cm}$ & \\
\hline & & ㅇ $81-88 \mathrm{~cm}$ & \\
\hline \multirow[t]{2}{*}{ Obese } & \multirow[t]{2}{*}{$\geq 30.0 \mathrm{~kg} / \mathrm{m}^{2}$} & $\hat{\delta}>102 \mathrm{~cm}$ & $\delta^{n} \geq 0.90$ \\
\hline & & $>>88 \mathrm{~cm}$ & $\{\geq 0.85$ \\
\hline
\end{tabular}

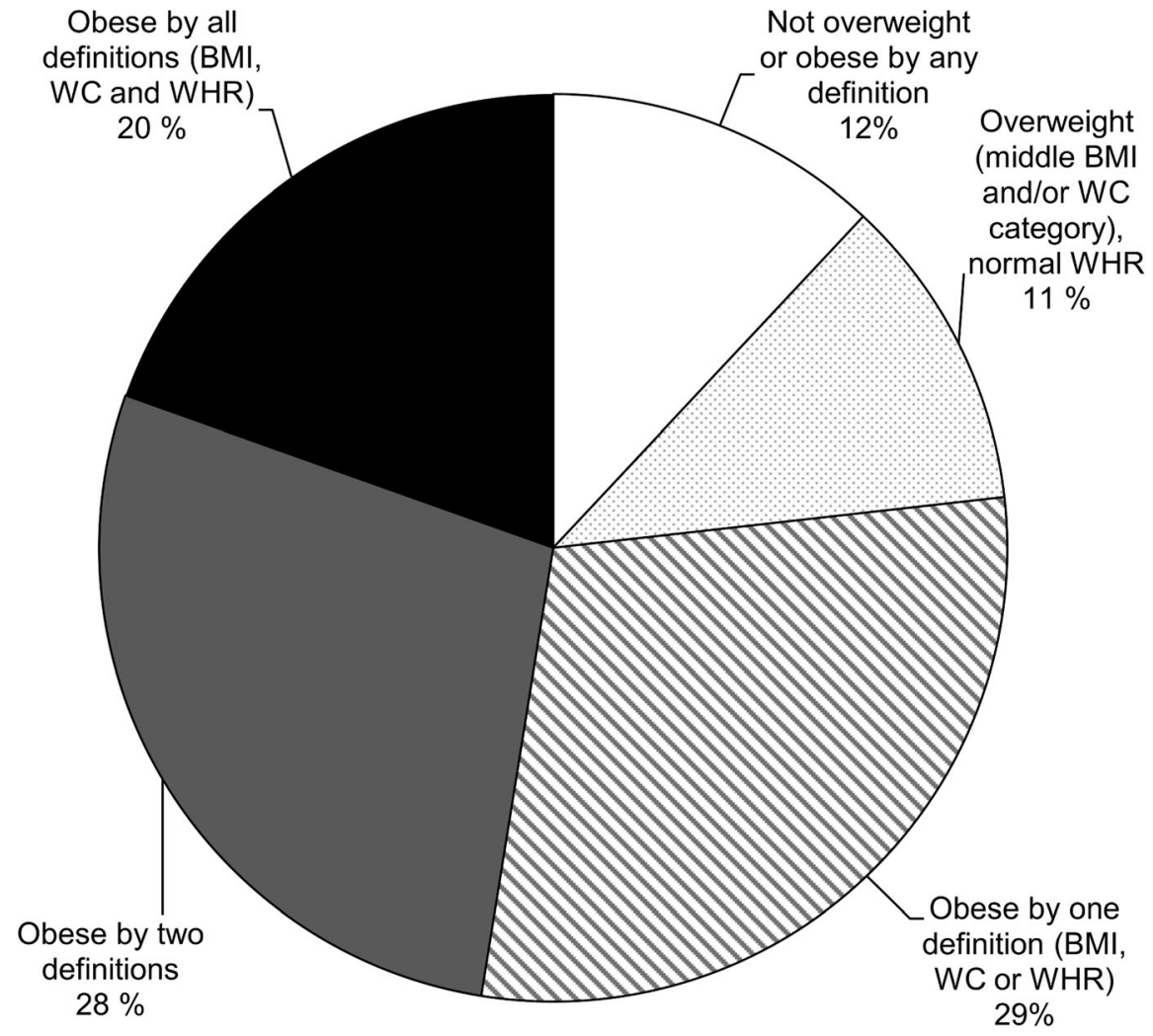

Fig. 3 Distribution of obesity in the RENIS-T6 cohort, by WHO categories for body mass index (BMI), waist circumference (WC) and the waist-hip ratio (WHR)

WC, was consistently associated with RHF, regardless of the RHF definition used. This finding suggests that excessive abdominal fat stores, as opposed to excess body weight distributed more evenly in the body, may potentially be more harmful to kidney function.

Most previous RHF studies with mGFR have found a positive relationship between BMI and RHF that disappears upon the adjustment of GFR to BSA [17-20]. The indexing of GFR to $1.73 \mathrm{~m}^{2}$ of BSA may be problematic in itself, particularly in the abnormal body sizes encountered when studying obese subjects [41]. Kwakernaak et al. found that the WHR predicted a lower BSA-adjusted mGFR when adjusted for BMI, age, sex and BP [18]. However, the sample size was small and consisted of kidney donors and volunteers, who may not be representative of the general population. Pinto-Sietsma et al. made a similar finding of higher WHR associated with lower GFR in a larger population, but the result was based on GFR estimated by creatinine clearance [22].

The hypothesis of hyperfiltration as a precursor to overt CKD, originally proposed by Brenner, is based on hyperfiltration in individual glomeruli [10]. Because it is not possible to measure single-nephron GFR directly in living humans, an indirect measure of hyperfiltration based on whole-kidney GFR must be used in epidemiological studies. Whole-kidney GFR is a function of single-nephron GFR and the total number of nephrons. Nephron numbers vary by gender and birth weight and decrease with age [42], and adult height has been shown 
Table 3 Odds ratios for renal hyperfiltration using alternative renal hyperfiltration definitions and variable models

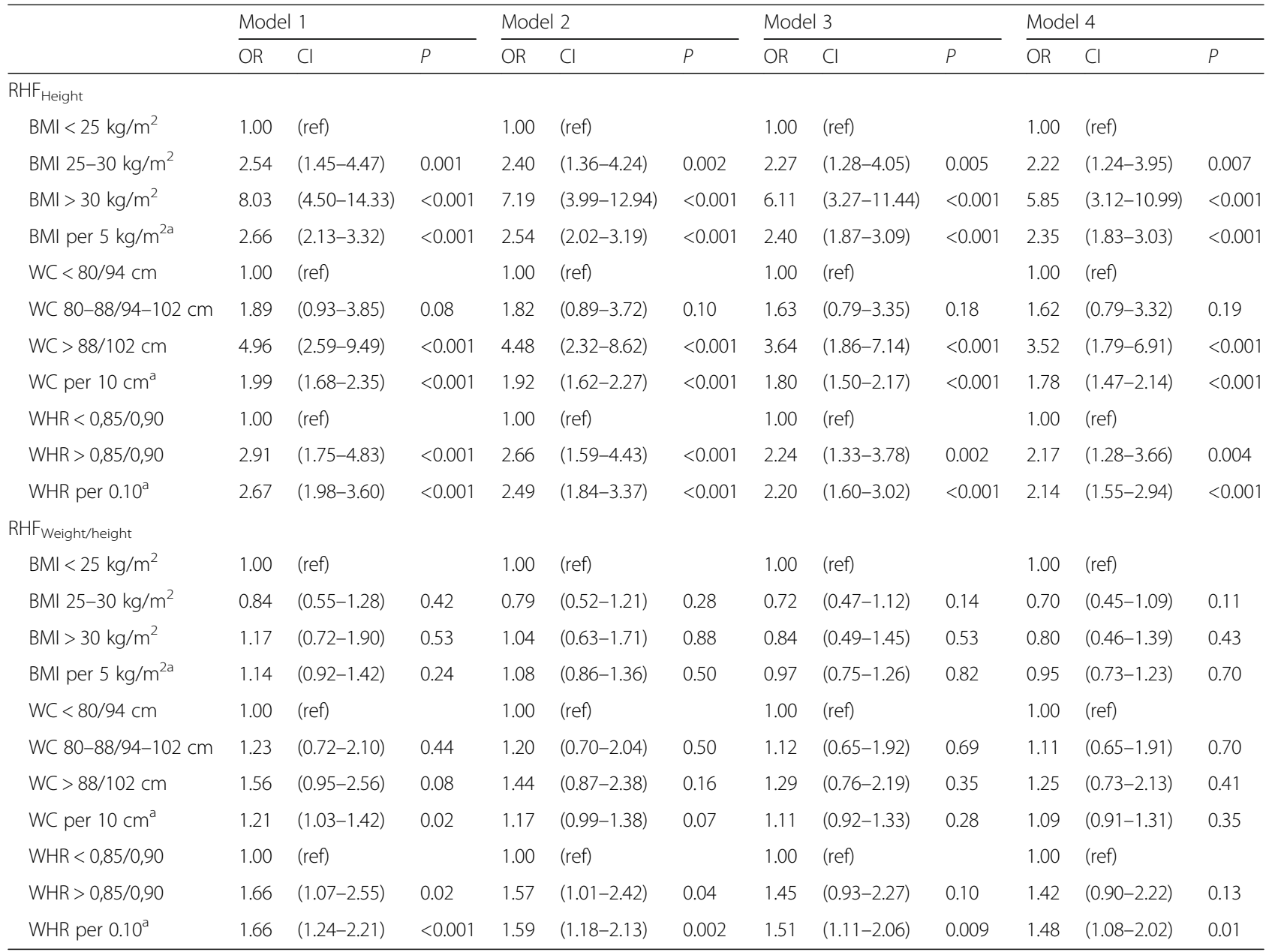

RHF Renal hyperfiltration, OR Odds ratio, Cl Confidence interval, BMI Body mass index, WC Waist circumference, WHR Waist-hip ratio

Model 1: Adjustment for age, sex, number of cigarettes smoked daily, ambulatory daytime systolic and diastolic BP (and their interaction), and individual categories of antihypertensive medication

Model 2: Model 1 and a dichotomous variable for a metabolically unhealthy lipid profile, defined as HDL-cholesterol levels $<1.03 \mathrm{mmol} / \mathrm{L}$ in men or $<1.29 \mathrm{mmol} / \mathrm{L}$ in women, elevated triglyceride levels of $\geq 1.7 \mathrm{mmol} / \mathrm{L}$, and/or use of lipid-lowering medication

Model 3: Model 1 plus fasting plasma glucose and insulin levels, and HOMA-IR

Model 4: All models combined

${ }^{a}$ continuous variable

to correlate with birth weight [43]. Thus, gender, height and age were included in both the RHF definitions (Table 1). RHF Height used the age-, sex- and heightspecific 90th percentile, and because an individual's normal body weight is correlated with height, it provides an indirect adjustment for a theoretical "normal" body size. $\mathrm{RHF}_{\text {Height }}$ is thus defined as excessive GFR relative to the mean GFR for a person with "normal" body weight. Because GFR increases with increasing body weight and increasing metabolic needs [44], it follows that $\mathrm{RHF}_{\text {Height }}$ is associated with measures of obesity, as shown in Table 3. However, when body weight was added as an independent variable to the same $\mathrm{RHF}_{\text {Height }}$ logistic regression models as in Table 3, the results were attenuated but remained essentially similar (Additional file 1: Table S3), indicating that an obese figure is associated with hyperfiltration independently of the effect of weight itself.

Another way to correct for interindividual variation in weight is to include weight in the definition of hyperfiltration, as in $\mathrm{RHF}_{\text {Weight/height }} \mathrm{RHF}_{\mathrm{Weight} / \text { height }}$ accordingly defines hyperfiltration as excessive GFR relative to the mean GFR for persons with a given height and weight, whether obese or not. This definition may underestimate hyperfiltration in obese subjects, and $\mathrm{RHF}_{\mathrm{Weight} / \text { height }}$ can be

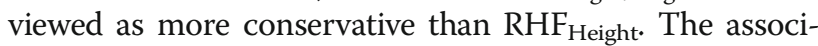
ation of WHR with hyperfiltration even when using $\mathrm{RHF}_{\text {Weight/height }}$ is a strong indicator that central obesity also entails hyperfiltration at the glomerular level.

The merits of different body size measurement methods in the context of epidemiological research and risk 
estimates for disease have been debated, as have the merits of various cut-off points [38]. BMI has become the dominant measure of obesity, partly due to its wellestablished association with several obesity-related diseases and partly due to the near-universal availability of height and weight as variables in both large population studies and general clinical practice. WHR, which measures body fat distribution rather than absolute body size, has been shown to be at least equal to, and often better than, BMI as a predictor for obesity-related disease including CKD [22, 45-47].

The mechanisms of the adverse renal effect of abdominal adiposity are not fully understood, but some effects are known. The most severe and well-established mediators are increased risks of diabetes mellitus, hypertension and dyslipidemia [48-50]. The effects of metabolic risk factors can be observed in our results, with a gradual attenuation of the odds ratio for RHF when variables for an unhealthy lipid profile and insulin resistance were included in the regression analyses.

Additionally, some other mechanisms are known, including dysfunction in the renin-angiotensin-aldosterone system, increased tubular sodium reabsorption, and the effects of obesity-related hormones and cytokines such as leptin, adiponectin and Tumor Necrosis Factor- $\alpha$ [48-50].

Weight loss interventions, especially bariatric surgery, have been shown to reduce GFR in hyperfiltrating obese subjects [51]. However, most studies of such interventions have been small, and few studies have been published on long-term effects beyond the first 2 years after the interventions. A recent study by Zingerman et al. suggested a possible reversal of RHF in obese patients using acetazolamide, although the study did not include a placebo arm [52].

The strength of the present study lies in the measurement of GFR with a gold-standard method in a large, representative, mostly healthy cohort in an age group susceptible to early stages of chronic diseases. To our knowledge, this is the largest cohort from the general population that has been studied using precise GFR measurements. The exclusion of subjects with diabetes, cardiovascular disease and renal disease from the study population allowed us to focus on the preliminary stages of potential future CKD with less confounding from these high-risk patient groups. These groups would have been more likely to have passed the transient stage of hyperfiltration into a state of normal-range GFR, perhaps accompanied by slight albuminuria.

There are several limitations to this study. First, it was a cross-sectional study and thus could not prove causation, only correlation. Second, the study population was exclusively Caucasian and middle-aged, which may limit the transferability of findings to other population groups. Furthermore, while GFR was measured with a gold standard method, obesity was measured indirectly with anthropometric data, and not directly with gold standard dual energy X-ray absorptiometry, computed tomography or magnetic resonance imaging methods. Glucose and HbA1c were only measured once to exclude diabetes, while regular clinical practice requires two measurements for the diagnosis.

\section{Conclusions}

We conclude that the WHR is associated with RHF, independently of other risk factors and even using $\mathrm{RHF}_{\text {Weight/height, a conservative, body size-adjusted RHF }}$ definition. Longitudinal studies are needed to explore whether RHF predicts future non-diabetic CKD. Further studies on whether the WHR predicts CKD better than other obesity measurements are also warranted.

\section{Additional file}

Additional file 1: Table S1. Regression models for the alternative renal hyperfiltration definitions. Table S2. mGFR cut-off points for renal hyperfiltration in male and female subjects from the study cohort with average height, weight and age. Table S3. Odds ratio for $\mathrm{RHF}_{\text {height, }}$ with body weight added as an independent variable. Table S4. Multiple linear regression with measured GFR and continuous obesity variables. (XLSX $22 \mathrm{~kb}$ )

\section{Abbreviations}

BMI: Body mass index; BP: Blood pressure; BSA: Body surface area; CKD: Chronic kidney disease; ESRD: End-stage renal disease; GFR: Glomerular filtration rate; HOMA-IR: Homeostatic model assessment of insulin resistance; MGFR: Measured glomerular filtration rate; RENIS-T6: Renal lohexol Survey in Tromsø 6; RHF: Renal hyperfiltration; WC: Waist circumference; WHR: Waisthip ratio

\section{Acknowledgements}

We would like to express our gratitude to our study subjects, who each devoted several hours of their time to make the study possible. We would like to thank Britt-Ann Winther Eilertsen, Bjørg Skog Høgset, Saskia van Heusden, and the rest of the staff at the Clinical Research Unit (University Hospital of North Norway (UNN)) for performing the study; Harald Strand and the staff at the Department of Medical Biochemistry (UNN) for HPLC analyses of iohexol; Inger Njølstad (Department of Community Medicine, UiT The Arctic University of Norway) and the rest of the staff of the Tromsø 6 population study; Inger Sperstad and Ingrid Dorthea Sandstad (Clinical Research Centre, UNN) for database support; and Tom Wilsgaard, Sriharan Sivasingarajah and Kurt Jøran Nyland (Department of Community Medicine, UiT The Arctic University of Norway) for identifying eligible subjects from the Tromsø 6 cohort.

This study was presented in abstract form at the 2015 Kidney Week of the American Society of Nephrology in San Diego, CA, USA.

\section{Funding}

The study was funded by the North Norway Regional Health Authority and a grant from UiT The Arctic University of Norway. The funding bodies had no role in the design of the study, nor the collection, analysis nor interpretation of data, or in writing this article.

\section{Availability of data and materials}

The authors prefer not to disclose the full dataset to the public domain due to study participants' privacy concerns. 


\section{Authors' contributions}

Research idea and study design: VTNS, BOE, TM; data acquisition: BOE, TM; data analysis/interpretation: VTNS, BOE, TM, JS, TGJ; statistical analysis: VTNS, BOE, TM; supervision or mentorship: BOE, TM, TGJ; critical review VTNS, BOE, TM, JS, TGJ. Each author contributed important intellectual content during manuscript drafting or revision and accepts accountability for the overall work by ensuring that questions pertaining to the accuracy or integrity of any portion of the work are appropriately investigated and resolved. All authors read and approved the final manuscript.

\section{Competing interests}

The authors declare that they have no competing interests.

\section{Consent for publication}

Not applicable.

\section{Ethics approval and consent to participate}

All participants provided informed, written consent, and the regional ethics committee of northern Norway approved the study, the reference number is REK NORD 89/2006. The study was in compliance with the WMA Declaration of Helsinki.

\section{Author details}

'Metabolic and Renal Research Group, Faculty of Health Sciences, UiT The Arctic University of Norway, Tromsø, Norway. ${ }^{2}$ Section of Nephrology, University Hospital of North Norway, Tromsø, Norway. ${ }^{3}$ Department of Organ Transplantation, Oslo University Hospital, Oslo, Norway.

Received: 21 June 2016 Accepted: 1 November 2016

Published online: 10 November 2016

\section{References}

1. Ng M, Fleming T, Robinson M, Thomson B, Graetz N, Margono C, Mullany EC, Biryukov S, Abbafati C, Abera SF, et al. Global, regional, and national prevalence of overweight and obesity in children and adults during 19802013: a systematic analysis for the Global Burden of Disease Study 2013. Lancet. 2014:384(9945):766-81.

2. Hubert HB, Feinleib M, McNamara PM, Castelli WP. Obesity as an independent risk factor for cardiovascular disease: a 26-year follow-up of participants in the Framingham Heart Study. Circulation. 1983;67(5):968-77.

3. Mokdad AH, Ford ES, Bowman BA, Dietz WH, Vinicor F, Bales VS, Marks JS. Prevalence of obesity, diabetes, and obesity-related health risk factors, 2001. JAMA. 2003;289(1):76-9.

4. Mann JF, Gerstein HC, Yi QL, Lonn EM, Hoogwerf BJ, Rashkow A, Yusuf S. Development of renal disease in people at high cardiovascular risk: results of the HOPE randomized study. J Am Soc Nephrol. 2003;14(3):641-7.

5. Klag MJ, Whelton PK, Randall BL, Neaton JD, Brancati FL, Ford CE, Shulman NB, Stamler J. Blood pressure and end-stage renal disease in men. N Engl J Med. 1996;334(1):13-8.

6. Brancati FL, Whelton PK, Randall BL, Neaton JD, Stamler J, Klag MJ. Risk of end-stage renal disease in diabetes mellitus: a prospective cohort study of men screened for MRFIT. Multiple Risk Factor Intervention Trial. JAMA. 1997; 278(23):2069-74

7. Fox CS, Larson MG, Leip EP, Culleton B, Wilson PW, Levy D. Predictors of new-onset kidney disease in a community-based population. JAMA. 2004; 291(7):844-50

8. Hsu CY, McCulloch CE, Iribarren C, Darbinian J, Go AS. Body mass index and risk for end-stage renal disease. Ann Intern Med. 2006;144(1):21-8.

9. Vivante A, Golan E, Tzur D, Leiba A, Tirosh A, Skorecki K, Calderon-Margalit R. Body mass index in 1.2 million adolescents and risk for end-stage renal disease. Arch Intern Med. 2012;172(21):1644-50.

10. Brenner BM, Lawler EV, Mackenzie HS. The hyperfiltration theory: a paradigm shift in nephrology. Kidney Int. 1996;49(6):1774-7.

11. Ruggenenti P, Porrini EL, Gaspari F, Motterlini N, Cannata A, Carrara F, Cella C, Ferrari S, Stucchi N, Parvanova A, et al. Glomerular hyperfiltration and renal disease progression in type 2 diabetes. Diabetes Care. 2012;35(10):2061-8.

12. Schmieder RE, Messerli FH, Garavaglia G, Nunez B. Glomerular hyperfiltration indicates early target organ damage in essential hypertension. JAMA. 1990; 264(21):2775-80
13. Okada R, Yasuda Y, Tsushita K, Wakai K, Hamajima N, Matsuo S. Glomerular hyperfiltration in prediabetes and prehypertension. Nephrol Dial Transplant. 2012;27(5):1821-5

14. Pinto-Sietsma SJ, Mulder J, Janssen WM, Hillege HL, de Zeeuw D, de Jong PE. Smoking is related to albuminuria and abnormal renal function in nondiabetic persons. Ann Intern Med. 2000;133(8):585-91.

15. Maeda I, Hayashi T, Sato KK, Koh H, Harita N, Nakamura Y, Endo G, Kambe H, Fukuda K. Cigarette smoking and the association with glomerular hyperfiltration and proteinuria in healthy middle-aged men. Clin J Am Soc Nephrol. 2011;6(10):2462-9.

16. Park M, Yoon E, Lim YH, Kim H, Choi J, Yoon HJ. Renal hyperfiltration as a novel marker of all-cause mortality. J Am Soc Nephrol. 2015;26(6):1426-33.

17. Kwakernaak AJ, Toering TJ, Navis G. Body mass index and body fat distribution as renal risk factors: a focus on the role of renal haemodynamics. Nephrol Dial Transplant. 2013;28 Suppl 4:iv42-49.

18. Kwakernaak AJ, Zelle DM, Bakker SJ, Navis G. Central body fat distribution associates with unfavorable renal hemodynamics independent of body mass index. J Am Soc Nephrol. 2013;24(6):987-94.

19. Wuerzner G, Pruijm M, Maillard M, Bovet P, Renaud C, Burnier M, Bochud M. Marked association between obesity and glomerular hyperfiltration: a crosssectional study in an African population. Am J Kidney Dis. 2010;56(2):303-12.

20. Peters AM, Perry L, Hooker CA, Howard B, Neilly MD, Seshadri N, Sobnack R, Irwin A, Snelling H, Gruning T, et al. Extracellular fluid volume and glomerular filtration rate in 1878 healthy potential renal transplant donors: effects of age, gender, obesity and scaling. Nephrol Dial Transplant. 2012;27(4):1429-37.

21. Ogna A, Forni Ogna V, Bochud M, Guessous I, Paccaud F, Burnier M, Wuerzner G. Association between obesity and glomerular hyperfiltration: the confounding effect of smoking and sodium and protein intakes. Eur J Nutr. 2016:55(3):1089-97.

22. Pinto-Sietsma SJ, Navis G, Janssen WM, de Zeeuw D, Gans RO, de Jong PE, Group PS. A central body fat distribution is related to renal function impairment, even in lean subjects. Am J Kidney Dis. 2003;41 (4):733-41.

23. Tomaszewski M, Charchar FJ, Maric C, McClure J, Crawford L, Grzeszczak W, Sattar N, Zukowska-Szczechowska E, Dominiczak AF. Glomerular hyperfiltration: a new marker of metabolic risk. Kidney Int. 2007;71(8):816-21.

24. Verhave JC, Hillege HL, Burgerhof JG, Gansevoort RT, de Zeeuw D, de Jong PE. The association between atherosclerotic risk factors and renal function in the general population. Kidney Int. 2005;67(5):1967-73.

25. Lee J, Kim HJ, Cho B, Park JH, Choi HC, Lee CM, Oh SW, Kwon H, Heo NJ. Abdominal adipose tissue was associated with glomerular hyperfiltration among non- diabetic and normotensive adults with a normal body mass index. PLoS One. 2015;10(10):e0141364.

26. Cachat F, Combescure C, Cauderay M, Girardin E, Chehade H. A systematic review of glomerular hyperfiltration assessment and definition in the medical literature. Clin J Am Soc Nephrol. 2015;10(3):382-9.

27. Melsom T, Mathisen UD, Ingebretsen OC, Jenssen TG, Njolstad I, Solbu MD, Toft I, Eriksen BO. Impaired fasting glucose is associated with renal hyperfiltration in the general population. Diabetes Care. 2011;34(7):1546-51.

28. Eriksen BO, Mathisen UD, Melsom T, Ingebretsen OC, Jenssen TG, Njolstad I, Solbu MD, Toft I. Cystatin C is not a better estimator of GFR than plasma creatinine in the general population. Kidney Int. 2010;78(12):1305-11.

29. Eriksen BO, Mathisen UD, Melsom T, Ingebretsen OC, Jenssen TG, Njolstad I, Solbu MD, Toft I. The role of cystatin C in improving GFR estimation in the general population. Am J kidney Dis. 2012;59(1):32-40.

30. Aggarwal N, Porter AC, Tang IY, Becker BN, Akkina SK. Creatinine-based estimations of kidney function are unreliable in obese kidney donors. J Transplant. 2012;2012:872894.

31. Mathisen UD, Melsom T, Ingebretsen OC, Jenssen T, Njolstad I, Solbu MD, Toft I, Eriksen BO. Estimated GFR associates with cardiovascular risk factors independently of measured GFR. J Am Soc Nephrol. 2011;22(5):927-37.

32. Melsom T, Fuskevag OM, Mathisen UD, Strand H, Schei J, Jenssen T, Solbu M, Eriksen BO. Estimated GFR is biased by non-traditional cardiovascular risk factors. Am J Nephrol. 2015;41(1):7-15.

33. Bird NJ, Peters C, Michell AR, Peters AM. Comparison of GFR measurements assessed from single versus multiple samples. Am J Kidney Dis. 2009;54(2):278-88.

34. Nilsson-Ehle P. lohexol clearance for the determination of glomerular filtration rate: 15 years' experience in clinical practice. eJIFCC. 2006;13(2):1-5. http://www.ifcc.org/ifccfiles/docs/130201005.pdf.

35. Jacobsson L. A method for the calculation of renal clearance based on a single plasma sample. Clin Physiol. 1983;3(4):297-305. 
36. Matthews DR, Hosker JP, Rudenski AS, Naylor BA, Treacher DF, Turner RC. Homeostasis model assessment: insulin resistance and beta-cell function from fasting plasma glucose and insulin concentrations in man. Diabetologia. 1985;28(7):412-9.

37. Mathisen UD, Melsom T, Ingebretsen OC, Jenssen TG, Njolstad I, Solbu MD, Toft I, Eriksen BO. Ambulatory blood pressure is associated with measured glomerular filtration rate in the general middle-aged population. J Hypertens. 2012;30(3):497-504.

38. World Health Organization. Waist Circumference and Waist-Hip Ratio: Report of a WHO Expert Consultation. Geneva, Switzerland: World Health Organization; 2008.

39. Alberti KG, Eckel RH, Grundy SM, Zimmet PZ, Cleeman JI, Donato KA, Fruchart JC, James WP, Loria CM, Smith Jr SC. Harmonizing the metabolic syndrome: a joint interim statement of the International Diabetes Federation Task Force on Epidemiology and Prevention; National Heart, Lung, and Blood Institute; American Heart Association; World Heart Federation; International Atherosclerosis Society; and International Association for the Study of Obesity. Circulation. 2009;120(16):1640-5.

40. Royston P, Sauerbrei W. MFP: Multivariable Model-Building with Fractional Polynomials. In: Multivariable Model-Building. edn.: Great Britain.: John Wiley \& Sons, Ltd; 2008: 115-150. http://www.wiley.com/WileyCDA/WileyTitle/ productCd-0470028424.html\#.

41. Delanaye P, Krzesinski JM. Indexing of renal function parameters by body surface area: intelligence or folly? Nephron Clin Pract. 2011;119(4):c289-292.

42. Hoy WE, Douglas-Denton RN, Hughson MD, Cass A, Johnson K, Bertram JF. A stereological study of glomerular number and volume: Preliminary findings in a multiracial study of kidneys at autopsy. Kidney Int. 2003; 63(S83):31-7.

43. Kuh D, Wadsworth M. Parental height: childhood environment and subsequent adult height in a national birth cohort. Int J Epidemiol. 1989;18(3):663-8.

44. Singer MA. Of mice and men and elephants: metabolic rate sets glomerular filtration rate. Am J Kidney Dis. 2001;37(1):164-78.

45. Elsayed EF, Sarnak MJ, Tighiouart H, Griffith JL, Kurth T, Salem DN, Levey AS, Weiner DE. Waist-to-hip ratio, body mass index, and subsequent kidney disease and death. Am J Kidney Dis. 2008;52(1):29-38.

46. Montague $\mathrm{CT}$, O'Rahilly $\mathrm{S}$. The perils of portliness: causes and consequences of visceral adiposity. Diabetes. 2000;49(6):883-8.

47. Kramer H, Gutierrez OM, Judd SE, Muntner P, Warnock DG, Tanner RM, Panwar B, Shoham DA, McClellan W. Waist Circumference, Body Mass Index, and ESRD in the REGARDS (Reasons for Geographic and Racial Differences in Stroke) Study. Am J Kidney Dis. 2016;67(1):62-9.

48. Hall JE, do Carmo JM, da Silva AA, Wang Z, Hall ME. Obesity-induced hypertension: interaction of neurohumoral and renal mechanisms. Circ Res. 2015;116(6):991-1006

49. Mathew AV, Okada S, Sharma K. Obesity related kidney disease. Curr Diabetes Rev. 2011;7(1):41-9.

50. Praga M, Morales E. Obesity, proteinuria and progression of renal failure. Curr Opin Nephrol Hypertens. 2006;15(5):481-6.

51. Bolignano D, Zoccali C. Effects of weight loss on renal function in obese CKD patients: a systematic review. Nephrol Dial Transplant. 2013;28 suppl 4:iv82-98.

52. Zingerman B, Herman-Edelstein $M$, Erman A, Bar Sheshet Itach S, Ori $Y$, Rozen-Zvi B, Gafter U, Chagnac A. Effect of acetazolamide on obesityinduced glomerular hyperfiltration: a randomized controlled trial. PLoS One. 2015;10(9):e0137163.

\section{Submit your next manuscript to BioMed Central and we will help you at every step:}

- We accept pre-submission inquiries

- Our selector tool helps you to find the most relevant journal

- We provide round the clock customer support

- Convenient online submission

- Thorough peer review

- Inclusion in PubMed and all major indexing services

- Maximum visibility for your research

Submit your manuscript at www.biomedcentral.com/submit
Biomed Central 